\title{
MEASURING BACTERIAL CELLS SIZE WITH AFM
}

\author{
Denise Osiro', Rubens Bernardes Filho²*, Odilio Benedito Garrido Assis², Lúcio André de Castro Jorge², Luiz Alberto \\ Colnago $^{2}$
}

\author{
${ }^{1}$ Centro Universitário da Fundação Educacional Guaxupé, Guaxupé, MG, Brasil; ${ }^{2}$ Embrapa Instrumentação, CNPDIA, São \\ Carlos, SP, Brasil.
}

Submitted: June 08, 2010; Approved: August 30, 2011.

\begin{abstract}
Atomic Force Microscopy (AFM) can be used to obtain high-resolution topographical images of bacteria revealing surface details and cell integrity. During scanning however, the interactions between the AFM probe and the membrane results in distortion of the images. Such distortions or artifacts are the result of geometrical effects related to bacterial cell height, specimen curvature and the AFM probe geometry. The most common artifact in imaging is surface broadening, what can lead to errors in bacterial sizing. Several methods of correction have been proposed to compensate for these artifacts and in this study we describe a simple geometric model for the interaction between the tip (a pyramidal shaped AFM probe) and the bacterium (Escherichia coli JM-109 strain) to minimize the enlarging effect. Approaches to bacteria immobilization and examples of AFM images analysis are also described.
\end{abstract}

Key words: Atomic force microscopy (AFM); Escherichia coli; cell dimensions; bacteria visualization

\section{INTRODUCTION}

Since its first design in 1986 as an exploratory device, the Atomic Force Microscopy (AFM) has evolved as an instrument for investigating biological materials with variable complexity such as tissues, yeasts, bacteria and their components, providing real-time in situ quantitative morphological information $(7,11)$. The AFM's versatility combines high resolution (less than $1 \mathrm{~nm}$ ) on a sample in native conditions, i.e., the ability to generate detailed images in air and even in liquid, with no conductive coating or staining applications (23).

The AFM principle is relatively simple: the object to be scanned is positioned under a fine tip held by a flexible spring (cantilever). The scanning is driven by a piezo ceramic that depending on the microscopy model, can move the specimen or the cantilever. A fine laser beam is reflected at the back-end of the cantilever and the position of the reflected beam is detected by a photodiode array. During scanning, the cantilever bending is registered and a topographical digital image is constructed representing both the repulsion and the attraction undergo by the tip. The resulting image represent the deflection of the cantilever $(\mathrm{Z})$ at each point of scanned area $(\mathrm{X}, \mathrm{Y})$. Further details of AFM operation can be found in the literature $(3,19)$.

Since AFM is instrument capable of non-destructively analysis, biological specimens such as cells, microorganisms and molecules can be three-dimensionally imaged with high

*Corresponding Author. Mailing address: Embrapa Instrumentação - CNPDIA, São Carlos, SP.; E-mail: rubens@ @npdia.embrapa.br 
resolution, providing significant information about structural, dimensional and functional properties under several physiological conditions and with superior details than those attained by conventional electronic scanning microscopy (13).

\section{Bacteria immobilization and AFM imaging}

In order to be imaged with AFM, bacteria must be anchored to a flat surface. Many strains of bacteria readily adhere to glass or other solid surfaces, but not all of them. Since immobilization must not affect the chemical and structural integrity of the cell surface, different approaches have been used for bacterial immobilization in AFM imaging. The most common and less inhibitive procedure is to dip a glass slide in a liquid bacterial culture and remove it after the specimen has had time to adhere, or to drop the solution on to surface and carry out the observation after spontaneous drying. In both methods the immobilization is ruled by weak electrostatic interactions (physical adsorption) to the slide surface, thus making it easy for the AFM probe to detach the cell from the substrate whilst scanning (12). To amend adherence and improve the ease of imaging, the substrate surface can be chemically modified by introducing polar groups that are receptive to the bacteria outer membrane, thus promoting covalent bonding. Organo-functional silanes, as for example 3-aminopropyl trimethoxysilane, are widely used to induce biological specimen adhesion. The silane substituent at one end reacts with hydroxyl groups on the substrate surface to give a polysiloxane polymeric layer. The organic substituent on the other end reacts with cell's carboxyl groups on cell membrane providing a covalent link (5).

Cleaved mica (Muscovite) has been commonly employed as a substrate and is considered a suitable surface for bacteria attachment. This material consists of tetrahedral double sheets of $(\mathrm{Si} / \mathrm{Al})_{2} \mathrm{O}_{5}$ electrostatically linked by potassium ions (general composition $\left.=\mathrm{KAl}_{2}(\mathrm{OH})_{2} \mathrm{AlSi}_{3} \mathrm{O}_{10}\right)$. When cleaved and hydrated, this gives rise to an atomically flat surface with high charge density and a well oriented crystal structure. The cleaved mica surface can be easily functionalized by silanization with alkoxysilanes in the presence of water, introducing cross-linking groups to the surface that promote irreversible adhesion of bacteria (14).

After immobilization, the AFM tip interacts with the scanned surface and creates a surface image. This image generally contains all metrological data and can be analyzed including height and distance measurements, roughness, cross section profile, and 3D visualization. Nevertheless, the geometrical interaction between AFM side size tip and cell surface causes image distortion when compared with the real surfaces. Since the final AFM image is the result of a convolution of the probe geometry and the shape of the cell being imaged, the dimensions of the objects are distorted, yielding overestimated values $(2,27)$. Several mathematical methods of different complexity have been proposed to correct or reduce such artifacts in bacterial sizing $(9,24,26)$. In this paper AFM analysis of immobilized E.coli on mica are presented and a simple approach to minimize tip-specimen distortion is proposed and discussed.

\section{MATERIALS AND METHODS}

Escherichia coli JM-109 (provided by Fundação Tropical André Tosello, Campinas, Brazil) was used as model bacterium. The microorganism was cultured overnight in LBmedium at $37^{\circ} \mathrm{C}$ in a shaker flask. An aliquot of a culture of was pelleted by centrifugation, washed in deionized water and resuspended in $3 \mathrm{ml}$ of tris- $\mathrm{HCl}$ buffer at $10^{8}$ c.f.u/ml. A $10 \mu \mathrm{l}$ droplet of this cell suspension was applied onto a freshly cleaved mica surface (first rinsed in ultrasonic bath and silanized with 3-aminopropyltriethoxysilane (APTES $\mathrm{NH}_{2}\left(\mathrm{CH}_{2}\right)_{3} \mathrm{Si}\left(\mathrm{OC}_{2} \mathrm{H}_{5}\right)_{3}$ - from Fluka). The surfaces were rinsed twice with tris- $\mathrm{HCl}$ buffer to remove non-adherent bacteria and allowed to dry spontaneously.

AFM images were recorded in contact modes using a Topometrix Discover System (model TMX-2100, Sebastopol, 
CA, USA) in air. A V-shaped cantilever with silicon nitride $\left(\mathrm{Si}_{3} \mathrm{~N}_{4}\right)$ pyramidal shaped tip (TopoMetrix, model 1520-000) was used. Random areas of 50 x $50 \mu \mathrm{m}$ were scanned and the images processed by a resident TOPOSPM software. Images were then processed in JPG format and directly imported into the image processing software SIARCS $^{\circledR}$ v. 3.0 for quantification in two dimensions.

SIARCS (Sistema Integrado para Análise de Raízes e Cobertura do Solo - Integrated System for Roots and Soil Coverage Analysis) is a image analysis software developed by Embrapa, originally designed for evaluate area and length measures in agricultural experimentation agricultural applications. SIARCS has several tools as automatic contour identification and numerical analyzes through graphs and columns. Details of the software can be found in http://www.cnpdia.embrapa.br/produtos/siarcs.html (22)

\section{RESULTS AND DISCUSSION}

A typical image of bacteria attached on sinalized mica is presented in Figure 1. The cells are random and dispersed over the scanned area, allowing individual assessment. A zoomed area can be selected and local analysis performed. In Figure 2 are displayed two small regions $(6 \times 6 \mu \mathrm{m})$ with a few organisms zoomed at closer range and 3D reconstructed. These examples visually confirm the integrity of the attached cells.

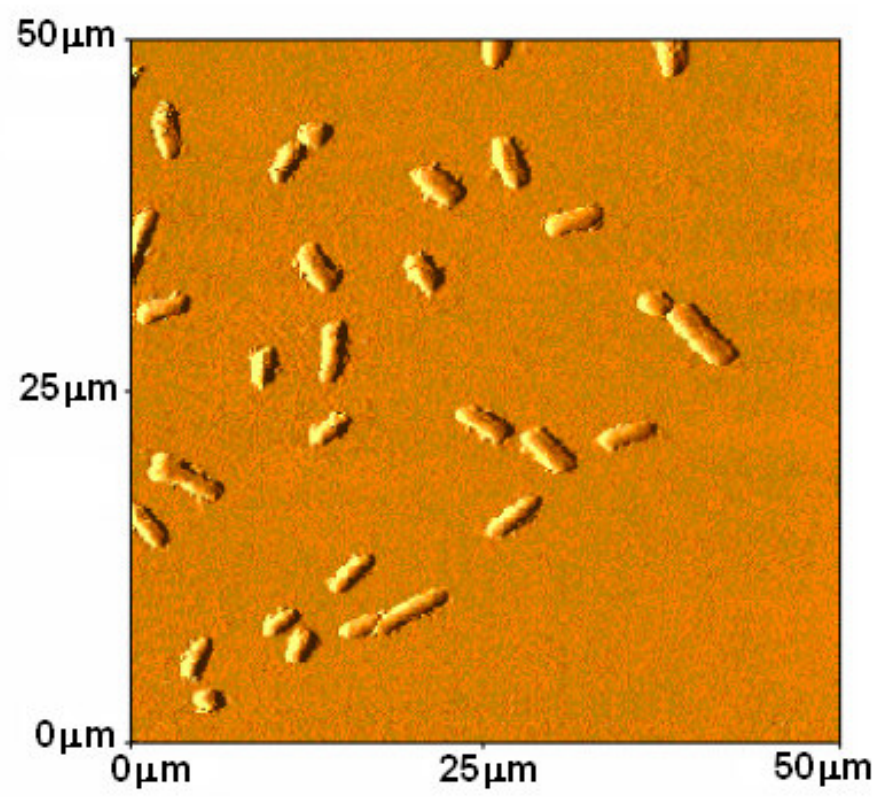

Figure 1. Example of AFM image of Escherichia coli on cleaved silanized mica. Topographic image processed using side illumination (Topospm software).
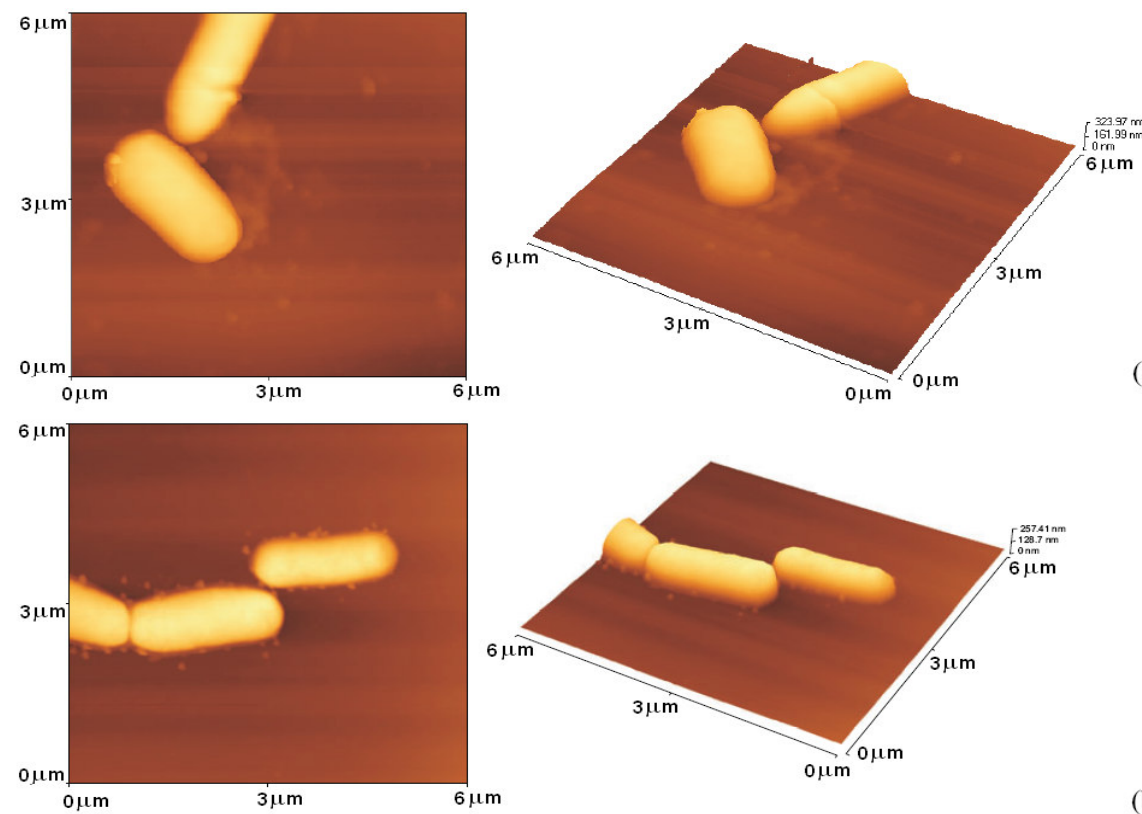

(a)

Figure 2. Closed observation of individual bacterias and corresponding $3 \mathrm{D}$ reconstructions. 
By using standard AFM software, individual analysis can be conducted providing a quantitative measurement of cell dimensions and surface roughness. Analytical examples for those images presented in Figure 2 are displayed in Figure 3, for which the height and the cross-sectional profile along the identified lines are presented. In general, the observed outer membranes of immobilized microorganisms were well structured and integrated, and there were no apparent indentations and grooves on cell surface. From height and section images the bacterial cells were observed to be relatively smooth, rod-shaped, $2.5 \mu \mathrm{m}$ long, $1.5 \mu \mathrm{m}$ in diameter and with middle high not exceeding $0.4 \mu \mathrm{m}$.
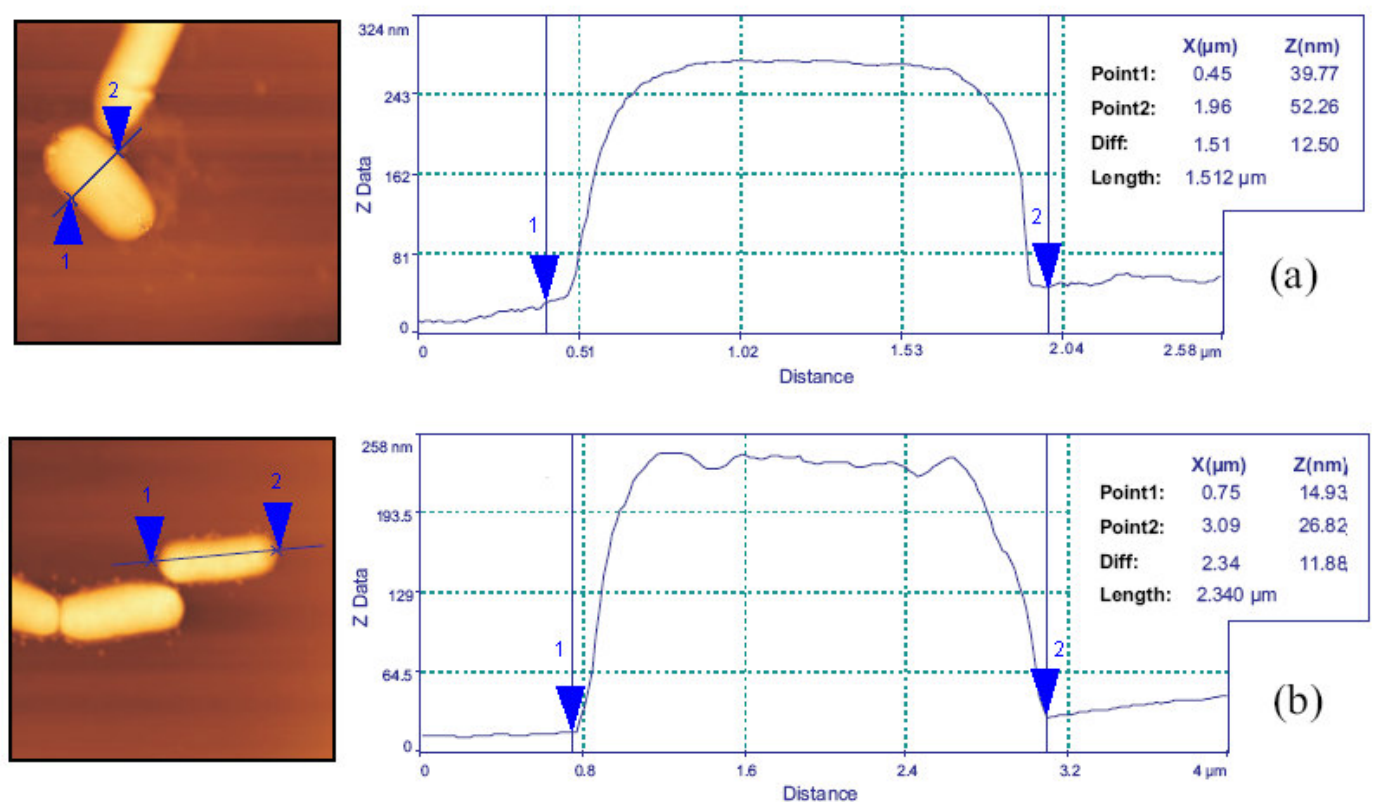

Figure 3. High-resolution AFM image and cross section measurement along the line shown in panel. Individual bacteria can be chosen and profile measured. In (a) a wide and in (b) a length measurement.
The AFM images gathered in this study were imported into SIARCS image analysis software. This software locates individual objects within an AFM image and measures their geometrical characteristics. This facilitates quick analysis of several individual objects, organizing measurements into large data sets of which can be analyzed statistically. By defining lower and upper threshold levels ranging from 0 (black) to 255 (white), the background signal can be removed. The result for the illustrative image (Figure 4) is sorted in ascending order by length in Table 1.
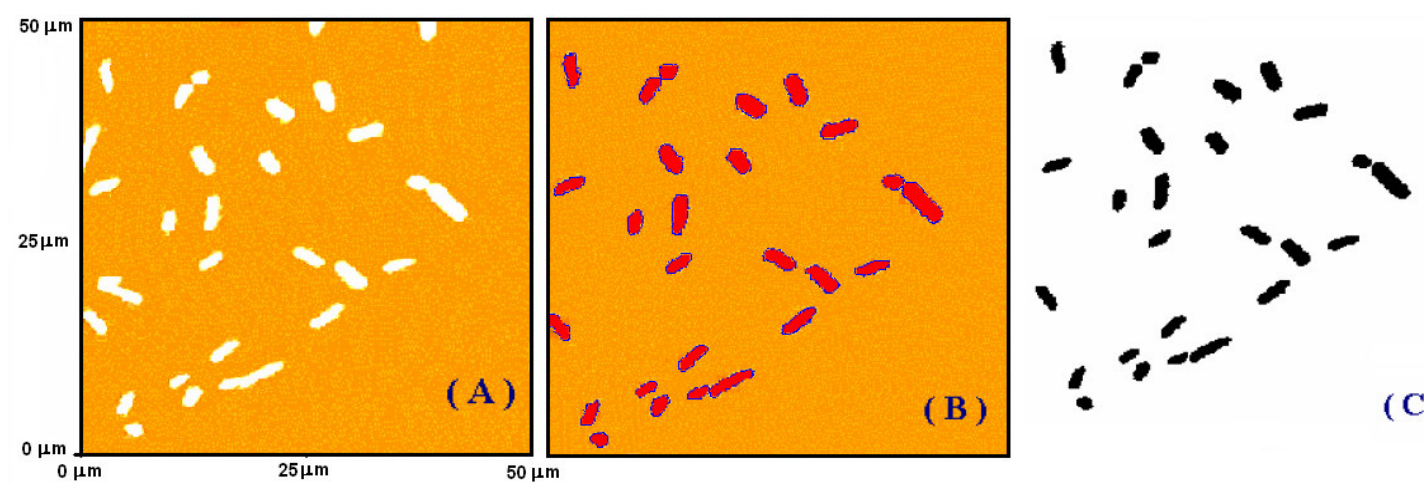

Figure 4. Example of image processing: (A) initial feature identification, marked automatically counted cells, and (C) the binarized image (the total (C) number of bacterial cells is 26) 
Table 1. Automatic measurements from cells of binarized exemple of Figure 4 (C).

\begin{tabular}{ccc}
\hline Bacterium & Length $(\boldsymbol{\mu} \mathbf{m})$ & Wide $(\boldsymbol{\mu m})$ \\
\hline 1 & 1.86 & 1.58 \\
2 & 2.15 & 1.58 \\
3 & 2.44 & 1.15 \\
4 & 2.44 & 1.58 \\
5 & 2.58 & 1.29 \\
6 & 2.58 & 1.72 \\
7 & 2.72 & 1.72 \\
8 & 3.01 & 1.86 \\
9 & 3.15 & 1.43 \\
10 & 3.15 & 1.43 \\
11 & 3.15 & 1.58 \\
12 & 3.58 & 1.43 \\
13 & 3.58 & 1.43 \\
14 & 3.58 & 1.86 \\
15 & 3.58 & 2.15 \\
16 & 3.72 & 1.43 \\
17 & 3.72 & 1.43 \\
18 & 3.72 & 1.72 \\
19 & 3.72 & 1.72 \\
20 & 3.72 & 2.01 \\
21 & 4.01 & 1.86 \\
22 & 4.15 & 1.58 \\
23 & 4.30 & 1.58 \\
24 & 4.44 & 1.86 \\
25 & 5.44 & 1.43 \\
26 & 5.44 & 2.01 \\
\hline
\end{tabular}

From several images analyzed and more than 200 bacterial cells computed, the average dimensions obtained were: length $3.71 \pm 0.18 \mu \mathrm{m}$ and wide $1.73 \pm 0.04 \mu \mathrm{m}$. It should be noted that images generated by an atomic force microscope are always a convolution of the probe geometry and the shape of the features being imaged. If the probe is greater than the feature examined, then the probe-generated artifact will be maximized and the dimensional measurements derived from the images will be inaccurate. In Figure 5 is shown a schematic picture of probe-cell interaction (20). As the AFM probe moves across the surface of a sample, it is prematurely lifted if the side of the probe is in contact with the sample instead of the apex. This lift introduces an error broadening the actual dimension.

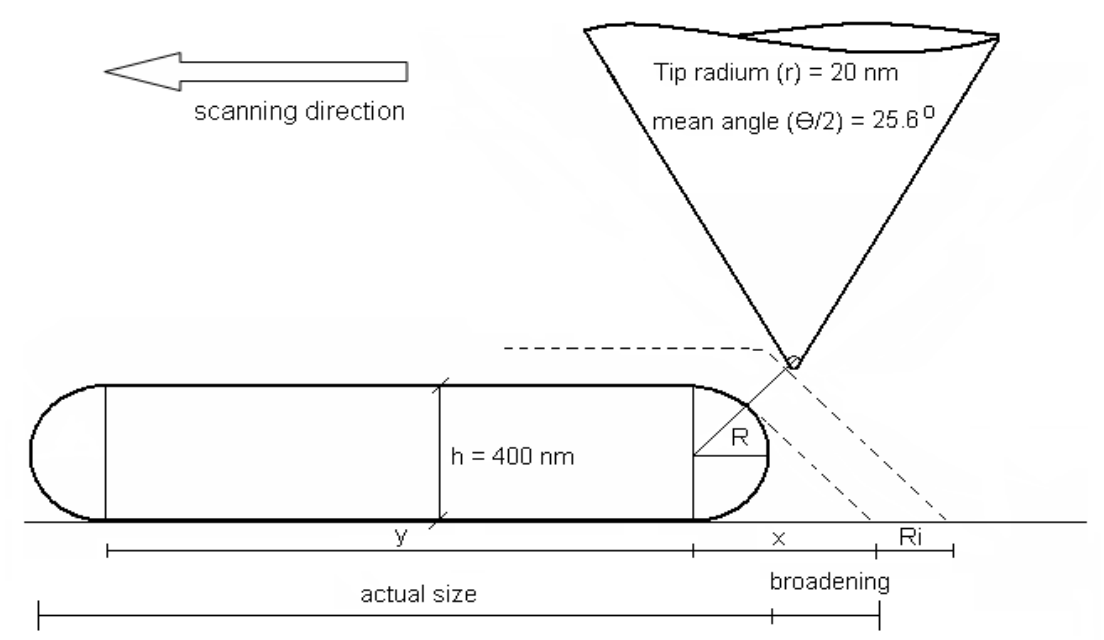

Figure 5. Motion of an AFM probe as it goes over a coliphorm bacterium attached to a flat surface. In such a measurement the side of the probe will cause a broadening in the image. 
The used tip has pyramidal shape with angle $\theta / 2=25.6^{\circ}$ and radium of $20 \mathrm{~nm}$ (TopoMetrix tip - supplier information). Bacterium height is considered to be $400 \mathrm{~nm}$ (average data from AFM individual measurements) so $R=h / 2=200 \mathrm{~nm}$. From Figure 5, geometrically can be estimated the broadening of bacterium image as $2(\mathrm{X}-\mathrm{R})$ where:

$$
X=R\{\cos (\theta / 2)+\tan (\theta / 2) \cdot[\sin (\theta / 2)+1]\}
$$

i,e., $X=420.68 \mathrm{~nm}$, so the calculated linear broadening is then $441.36 \mathrm{~nm}(0.441 \mu \mathrm{m})$ in each direction. Considering that the location of the artifact did not change when the scan direction changed (26), the adjusted average dimensions are $3.26 \mu \mathrm{m}$ length by $1.28 \mu \mathrm{m}$ wide. It is worth noticing that proportionally the tip radium is considerable shorter when compared to the bacteria dimensions. The image will essentially be ruled by the tip geometry rather than by the tip radium, which can be neglected with no loss of accuracy.

Our resulting size are in good agreement with other $E$. coli AFM measurements as presented by Amro et al., (1); Qian et al., (21) and Silva \& Teschk (25) though still larger than the actual E. coli dimensions established as $2.0 \mu \mathrm{m}$ length by 0.8 $1.0 \mu \mathrm{m}$ wide (15).

One point to take into account in sizing rod-shaped bacteria is the increasing of two-dimensional size while attaching to flat surface. When a bacterium comes near to a surface the attraction is ruled by the interaction between physicochemical bacterial wall and solid substratum. According to Fletcher (8), the initial adhesion can be caused by nonspecific adsorption. Then once the contact has occurred the cell tries to accommodate on the surface such that it strengthens and stabilizes immobilization. The greater the affinity towards the surface, the higher will be the lateral walls elongation to bind to a greater number of interacting points as possible. The final bacterium conformation will reflect the affinity of the surface lipopolysaccharide or outer membrane proteins to attach to the solid surface (4).
The morphology of the bacteria after immobilization has been examined by means of high-resolution scanning electron microscope (6) and clearly related the shape of the immobilized colonies to the solid surface features. The level of bacteria to adhere to different surfaces is based on physicochemical characteristics of the bacterial surface and substrate such as wettability and charge density (10, 18). According to this concept, E. coli cells exhibit a greater propensity to adhere to hydrophilic based surfaces, such as silanized mica, resulting in an increase in two-dimensional size while attaching to the surface (17). Treated mica is energetically favorable facilitating the bacterium approach and short-range attractive interaction. The presence of many attaching sites leads the bacteria to attain a maximum adherence as possible resulting in a flattened pattern. AFM analysis have shown that morphology of bacteria after mica immobilization, registered an attachment pattern with large or elongated cells, around 40\% in length and 30\% in wide (16), what is in perfect agreement to results here presented.

\section{CONCLUSION}

Atomic force microscopy is a powerful tool for studying bacteria cells features. It provides high resolution topographic images as well as quantitative information about surface and morphology. However, the discrepancy caused primarily by the distortion of the images of individual cells due to the finite size of the AFM tip, results in enlargement of the lateral dimensions of bacterium cell. By applying a simple geometrical relationship, the artifact can be minimized and the error in the calculated dimensions reduced. Nevertheless, two dimensional cell enlargements due to bacterium and substrate affinity after adhesion have also to be considered.

\section{REFERENCES}

1. Amro, N.A.; Kotra, L.P.; Wadu-Mesthrige, K.; Bulychev, A.; Mobashery, S.; Liu, G.-Y. (2000). High-Resolution Atomic Force 
Microscopy Studies of the Escherichia coli Outer Membrane: Structural Basis for Permeability. Langmuir. 16, 2789-2796.

2. Bernardes-Filho, R.; Assis, O.B.G. (2005). Development of an Algorithm for Tip-related Artifacts Identification in AFM Biological Film Imaging. Braz. Arch. Biol. Technol., 48, 667-674.

3. Binnig. G.; Quate, C.F.; Gerber, C. (1986). Atomic force microscope Phys. Rev. Lett., 56, 930-933.

4. Boman, H.G.; Monner, D.A. (1975). Characterization of lipopolysaccharides from Escherichia coli K-12 mutants. J. Bacteriol., $121,455-464$

5. Camesano, T., Logan, B. E. (2000). Probing bacterial electrosteric interactions using atomic force microscopy. Environ. Sci. Technol., 34, 3354-3362.

6. Díaz, C.; Cortizo, M.C.; Schilardi, P.L.; Saravia, S.G.G.; Mele, M.A.F.L. (2007). Influence of the Nano-micro Structure of the Surface on Bacterial Adhesion. Materials Research., 10, 11-14.

7. Dufrêne, Y.F. (2002). Atomic force microscopy, a powerful tool in microbiology. J. Bacteriol., 184, 5205-5213.

8. Fletcher, M. (1996). Bacterial attachment in aquatic environments: A diversity of surfaces and adhesion strategies. In: Fletcher, M. (ed). Bacterial adhesion: Molecular and ecological diversity. Willey-Liss Inc., New York, USA, Chapter 1, pp. 1-24.

9. Gainutdinov, R.V.; Arutyuno P.A. (2001). Artifacts in Atomic Force Microscopy. Russian Microelectronics. 30, 219-224.

10. Gallardo-Moreno, A.M.; Gonzalez-Martín, M.L.; Pérez-Giraldo, C.; Bruque, J.M.; Gómez-García, A.C. (2002). Serum as a Factor Influencing Adhesion of Enterococcus faecalis to Glass and Silicone. Appl. Environ. Microbiol., 68, 784-5787.

11. Ikai, A. (1996). STM and AFM of bio/organic molecules and structure. Surface Science Reports, 26, 261-332.

12. Kailas, L.; Ratcliffe, E.C.; Hayhurst, E.J.; Walker, M.G.; Foster, S.J.; Hobbs, K. (2009). Immobilizing live bacteria for AFM imaging of cellular processes. Ultramicroscopy. 109, 775-780.

13. Kasas, S.; Thomson, N.H.; Smith, B.L.; Hansma, P.K.; Miklossy, J.; Hansma, H.G. (1997). Biological applications of the AFM: from single molecules to organs. Int. J. Imaging Syst.Technol. 8, 151-161.

14. Lyubchenko, Y.L.; Jacobs, B.L.; Lindsay, S.M.; Stasiak, A. (1995). Atomic force microscopy of nucleoprotein complexes. Scanning Microscopy. 9, 705-727.
15. Meztler, D.E.; Meztler, C.M. (1997). Biochemistry: The chemical reactions of living cells. Hartcourt Academic Press, London, UK, v.1.

16. Mitik-Dineva, N.; Wang, J.; Mocanasu, R.C.; Stoddart, P.R.; Crawford, R.J.; Ivanova. E. P. (2008). Impact of nano-topography on bacterial attachment. Biotechnol. J., 3,536-544.

17. Mitik-Dineva, N.; Wang. J.; Truong, V.K.; Stoddart, P.; Malherbe. F.; Crawford, R.J.; Ivanova. E. P. (2009). Escherichia coli, Pseudomonas aeruginosa, and Staphylococcus aureus Attachment Patterns on Glass Surfaces with Nanoscale Roughness. Curr. Microbiol., 58,268-273.

18. Morais, L.C.; Bernardes-Filho, R.; Assis, O.B.G. (2009). Wettability and bacteria attachment evaluation of multilayer proteases films for biosensor application. World J. Microbiol. Biotechnol., 25,123-129.

19. Morris, V.J.; Kirby, A.R.; Gunning, A.P. (1999). Atomic Force Microscopy for Biologists. London: Imperial College Press.

20. Osiro, D. (1998). Análise de vírus e bactérias por microscopia de força atômica. São Carlos, Brazil, (M.Sc. Dissertation. Instituto de Química de São Carlos. USP).

21. Qian, L.; Guan, Y.; He, B.; Xiao. H. (2008). Modified guanidine polymers: Synthesis and antimicrobial mechanism revealed by AFM. Polymer. 49, 2471-2475.

22. SIARCS. Sistema Integrado para Análise de Raízes e Cobertura do Solo. Available at: http://www.cnpdia.embrapa.br/produtos/siarcs.html. Accessed 15 Oct 2010.

23. Schabert, F.A.; Henn C.; Engel, A. (1995). Native Escherichia coli OmpF porin surfaces probed by atomic force microscopy. Science. 268 , 92-94.

24. Shen, Y.; Sun, J.L.; Zhang, A.; Hu, J.; Xu, LX. (2007). A new image correction method for live cell atomic force microscopy. Phys. Med. Biol., 52, 2185-2196.

25. Silva Jr., A.; Teschke, O. (2005). Dynamics of the antimicrobial peptide PGLa action on Escherichia coli monitored by atomic force microscopy. World J. Microbiol. Biotechnol., 21, 1103-1110.

26. Velegol, S.B.; Pardi, S.; Li, X.; Velegol, D.; Logan, B.E. (2003). AFM Imaging artifacts due to bacterial cell height and AFM tip geometry. Langmuir. 19, 851-857.

27. Yang, D-Q.; Xiong, Y-Q.; Guo, Y.; Da, D-A.; Lu, W-G. (2001) Sizes correction on AFM images of nanometer spherical particles. J. Materials Sci., 36, 263-267. 